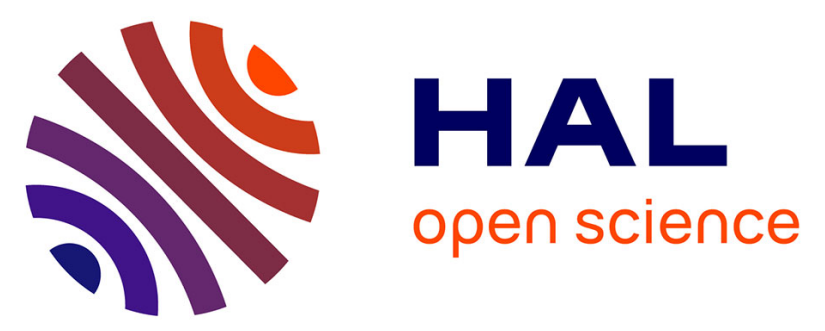

\title{
Scenario modelling of carbon mineralization in 3D soil architecture at the microscale: Toward an accessibility coefficient of organic matter for bacteria
}

Bruno Mbé, Olivier Monga, Valérie Pot, Wilfred Otten, Frédéric Hecht, Xavier Raynaud, Naoise Nunan, Claire Chenu, Philippe Baveye, Patricia Garnier

\section{To cite this version:}

Bruno Mbé, Olivier Monga, Valérie Pot, Wilfred Otten, Frédéric Hecht, et al.. Scenario modelling of carbon mineralization in 3D soil architecture at the microscale: Toward an accessibility coefficient of organic matter for bacteria. European Journal of Soil Science, 2022, 73, pp.e13144. 10.1111/ejss.13144 . hal-03365963

\section{HAL Id: hal-03365963 \\ https://hal.science/hal-03365963}

Submitted on 5 Oct 2021

HAL is a multi-disciplinary open access archive for the deposit and dissemination of scientific research documents, whether they are published or not. The documents may come from teaching and research institutions in France or abroad, or from public or private research centers.
L'archive ouverte pluridisciplinaire HAL, est destinée au dépôt et à la diffusion de documents scientifiques de niveau recherche, publiés ou non, émanant des établissements d'enseignement et de recherche français ou étrangers, des laboratoires publics ou privés. 


\title{
Scenario modelling of carbon mineralization in 3D soil architecture at the microscale: toward an accessibility coefficient of organic matter for bacteria
}

\section{Running title: $\mu \mathrm{m}$-modelling scenarios of $\mathrm{C}$ mineralisation}

\begin{abstract}
Bruno Mbé1,2, Olivier Monga ${ }^{3}$, Valérie Pot ${ }^{1}$, Wilfred Otten ${ }^{4}$, Frédéric Hecht ${ }^{5}$, Xavier Raynaud $^{6}$, Naoise Nunan ${ }^{6}$, Claire Chenu ${ }^{1}$, Philippe C. Baveye ${ }^{1,7}$, Patricia Garnier ${ }^{1 *}$
\end{abstract}

${ }^{1}$ Univ Paris-Saclay, INRA, AgroParisTech, UMR ECOSYS, Avenue Lucien Brétignières, 78500 Thiverval-Grignon, France.

${ }^{2}$ Univ Yaounde I, SAM Team, UMMISCO, POB 812, Yaounde, Cameroon

${ }^{3}$ Sorbonne Univ, IRD, UMMISCO, F-93143 Bondy, France

${ }^{4}$ Cranfield Univ, Sch Water Energy \& Environm, Cranfield MK43 0AL, Beds, England

${ }^{5}$ Univ Paris Diderot SPC, Sorbonne Univ, CNRS, Lab Jacques Louis Lions, F-75005 Paris, France

${ }^{6}$ Univ Paris, Sorbonne Univ, IEES Paris, UPEC,CNRS,IRD,INRA,UMR 7618, 4 Pl Jussieu, F75005 Paris, France

${ }^{7}$ Saint Loup Research Institute, La Grande Romelière, 7 rue des chênes, 79600 Saint Loup Lamairé, France

Keywords: model scenarios, tomography, soil structure, decomposition, diffusion

\footnotetext{
${ }^{*}$ Corresponding author Patricia Garnier. E-mail: Patricia.Garnier@inrae.fr

This article has been accepted for publication and undergone full peer review but has not been through the copyediting, typesetting, pagination and proofreading process which may lead to differences between this version and the Version of Record. Please cite this article as doi: 10.1111/ejss.13144
} 


\section{Abstract}

The microscale physical characteristics of microbial habitats considerably affect the decomposition of organic matter in soils. One of the challenges is to identify microheterogeneities in soil that can explain the extent of carbon mineralization. The aim of this study was therefore to identify descriptors of $\mu \mathrm{m}$-scale soil heterogeneity that can explain $\mathrm{CO}_{2}$ fluxes obtained at the mm scale. A suite of methods and models that visualize soil heterogeneity at scales relevant to microorganisms has been developed over the last decade. Among the existing 3D models that simulate microbial activity in soils, Mosaic is able to simulate, within a short computation time, the microbial degradation of organic matter at the microhabitat scale in soil using real 3D images of soil porosity. Our approach was to generate scenarios of carbon mineralization for various microscale environmental conditions and determine how the descriptors of soil structure could explain $\mathrm{CO}_{2}$ evolution. First, we verified that the simulated diffusion of solutes in the soil samples obtained with Mosaic were the same as those obtained using the same parameter set from a robust 3D model based on a lattice Boltzmann approach. Then, we ran scenarios considering different soil pore architectures, water saturations and microorganism and organic matter placements. We found that the $\mathrm{CO}_{2}$ emissions simulated for the different scenarios could be explained by the distance between microorganisms and organic matter, the diffusion of the substrate and the concentration of the available substrate. For some of the scenarios, we proposed a descriptor of accessibility based on the geodesic distance between microorganisms and organic matter weighted by the amount of organic matter. This microscale descriptor is correlated to the simulated $\mathrm{CO}_{2}$ flux with a correlation coefficient of 0.69 . 


\section{Introduction}

Reducing greenhouse gas emissions by improving the efficiency of agricultural systems through robust ecologically based management practices represents one of the most important challenges facing agriculture today. Models are needed to evaluate the effects of soil properties, climate conditions, and agricultural management practices on the soil carbon and nitrogen transformations responsible for greenhouse gas emissions and carbon sequestration. However, models of carbon and nitrogen cycles in soils are not predictive enough because they ignore the high level of microbial habitat heterogeneity at the pore scale where microorganisms transform organic substrates by mineralizing carbon and nitrogen (Manzoni and Porporato, 2009, Dungait et al., 2012).

The distribution of the heterogeneity of minerals, pores, organic matter and microorganisms in soil occurs at fine scales of a few $\mu$ m (Rawlins et al., 2016, Kravchenko and Guber, 2017, Baveye et al., 2018). The access of microorganisms to macromolecular soil organic matter is dependent on the hydrolysis of organic molecules by exoenzymes and the diffusive transport of the resulting assimilable carbon in the soil solution from locations of exoenzymatic action to microorganisms (Pagel et al., 2020). The properties of the pore space, such as pore connectivity and tortuosity, affect the water distribution and consequently the diffusion pathways that may control the access of decomposers to organic substrates (Vogel et al., 2015). Several experimental studies (e.g., Juarez et al., 2013, Pinheiro et al., 2015) suggest that there is a link between the local accessibility of microbial degraders to substrates and carbon mineralization fluxes.

One of the challenges in this area is to identify key descriptors of soil microheterogeneity that can explain the extent of $\mathrm{CO}_{2}$ emissions. Several authors have already contributed to the search for suitable descriptors. Garnier et al. (2008) proposed a parameter that takes into account the contact surface between organic matter and soil, and organisms were 
assumed to be distributed in the soil around the organic matter. Rawlins et al. (2016) tried to determine the accessibility of organic matter by using 3D- $\mu \mathrm{CT}$ images of stained organic matter in a soil structure and compute the transition probabilities between adjacent organic matter and pore voxels. They used the organic matter-pore transition probabilities as an index of soil organic matter accessibility. However, they found a weak linear correlation between this organic matter accessibility index and the microbial respiration measured on the same soil samples. Using a simple 2D model of organic matter decomposition, Chakrawal et al. (2020) proposed an analytical scale transition approach in which microscale heterogeneities affect the mean respiration rate through second-order spatial moments. However, their biological model did not consider diffusive fluxes, and further research may therefore be needed to develop a more realistic model, which at that stage may, however, become too complex to handle with the volume-averaging technique they were employing. Another possibility to identify the relevant descriptors of soil microstructure would be to use existing 3D pore-scale models of soil organic matter mineralization to run a series of scenarios with contrasting microscale conditions and test which descriptors of soil microheterogeneity correlate with the evolved $\mathrm{CO}_{2}$.

In the last decade, several innovative 3D models have been developed to describe the physicochemical processes occurring in soil pores at scales directly relevant to microorganisms (see Baveye et al., 2018). These models are able to explicitly describe pore geometry and topology using 3D computed tomography (CT) images of soils and simulate numerous spatial interactions between physical, chemical and biological components of soil within and between pores. They can calculate the 3D distribution of water, diffusion of carbon, and microbial growth in soil pores, as well as the $\mathrm{CO}_{2}$ flux due to respiration. Some models, based on the lattice-Boltzmann method, can directly use the voxel-based description of the soil porosity extracted from 3D CT images as model input (e.g., Falconer et al., 2012; Vogel et al., 2015). However, simulating the dynamics of microbial activity from 3D images with 3D models is 
very challenging because this approach faces limitations due to the computational cost of describing the 3D heterogeneities of soil at the $\mu \mathrm{m}$ scale to produce output at the cm core scale. The management of large numerical data sets is one of the key factors determining the ability to run 3D numerical models using real soil images. The Mosaic model tackles this problem using a different approach based on advanced 3D computer vision and shape modelling algorithms (Ngom et al., 2011, Monga et al. 2014). To do so, the Mosaic model approximates a soil's pore space using a limited number of geometrical shapes or primitives.

Such pore-scale models have been used to simulate various scenarios, which showed that the microscale organization explained the simulated cm-scale $\mathrm{CO}_{2}$ fluxes, thereby generating a range of scenarios in which microorganisms and substrates are distributed in a variety of ways, more or less heterogeneously, in the pore space of different soil structures. For example, using a lattice Boltzmann approach, Vogel et al. (2015) found that the interactions between water content, pore geometry and substrate-microorganism distance could explain the variability in the amount of organic carbon mineralized. In particular, low water contents led to disconnection between pores that limited the access of microorganisms to organic matter. Falconer et al. (2012), while simulating 3D fungal propagation in soil, showed that increasing the water saturation of soil samples decreased fungal colonization because of the decrease in connected air-filled pores in which fungi spread preferentially. They found that fungal spread in soil was more sensitive to the local water distribution than to the bulk degree of water saturation. Portell et al. (2018; using an individual-based approach) and Pagel et al. (2020; using a trait-based model) found that the degree of spatial heterogeneity of microbial communities determined the mineralization degree of carbon from soil samples. The question is whether, with this type of scenario modelling, we can propose and test descriptors of soil microscale organization to explain macroscopic $\mathrm{CO}_{2}$ fluxes. 
In this general context, the objective of the research described in this manuscript was to carry out simulation scenarios at the 3D-pore scale and find factors that allow us to link the simulated flux and microscopic organization of soil. For this, we used the 3D $\mu \mathrm{m}$-scale Mosaic model, which has the advantage of requiring a low computation time, even when using large 3D images of soil porosity. In the first step, we improved the Mosaic model to better describe the soil pore connectivity by comparing its outputs with those from a lattice Boltzmann model already tested for its ability to describe this process (Genty \& Pot, 2014). We built scenarios using published 3D CT images of soil compacted at different densities (Juyal et al., 2018) in which we distributed the microorganisms using the model of Raynaud \& Nunan (2014). We used the biological parameters calibrated from incubation experiments (Monga et al., 2014). The factors that we modified in the scenarios were the soil bulk density, water content, and spatial distribution of microorganisms and organic matter. Finally, from some of the model outputs, we proposed and calculated accessibility coefficients that we correlated to $\mathrm{CO}_{2}$ evolution.

\section{Material and methods}

\subsection{Mosaic Model}

\subsubsection{Presentation}

Because of its compact representation of pore spaces, the Mosaic model (Monga et al. 2008) can be run for a large number of modelling scenarios during a reasonable computing time. It has already been tested for its ability to distribute water in the pore space of unsaturated soil (Pot et al., 2015) and simulate the decomposition of organic matter in sand (Monga et al., 2014). In both studies, a comparison between simulated and experimental results was successfully carried out. However, its ability to simulate diffusion has not yet been tested.

In the Mosaic model, pore space is approximated by a set of geometric primitives (spheres) using algorithmic geometry based on Delaunay triangulation (Monga et al., 2008). In the 
procedure used to define the spheres, the first step is to determine the set of maximum-sized spheres contained in the pixels associated with the pore space in the 3D tomographic image of a soil sample. Then, a minimum set of maximum spheres is extracted to obtain a representation of the pore space that is as compact as possible. From this set of spheres, an attributed adjacency valuated graph is calculated in which each node is attached to a sphere and each arc corresponds to an adjacency between two spheres. The union of all spheres recovers the pore space up to rounded errors due to numerical approximation.

\subsubsection{Model improvement}

In the work described here, the pore network's connectivity has been increased compared to previous research using Mosaic (Monga et al., 2014) to obtain diffusion curves that are as close as possible to those simulated with the lattice Boltzmann model (LBM model in the following) of Genty and Pot (2014), which was already tested for diffusion. First, a graph with an initial connectivity was calculated from the 3D image (Fig. 1a). To improve the connectivity, we proceeded to a second 3D Delaunay triangulation of the centres of the spheres, linking each sphere to the closest sphere (the first Delaunay triangulation was used to obtain the maximum balls). We obtained a tetrahedron between the centres of neighbouring spheres with a greater connectivity than that previously reported (Fig. 1b with black connections) because Delaunay triangulation provided a complementary set of adjacencies compared to the

initial situation (Fig. 1c). Finally, a postprocessing treatment was applied (Fig. 1d), during which the connections that did not belong to the pore space were removed. This new algorithm increased the connectivity of the Mosaic model compared to previous versions (Monga et al., 2014) by connecting spheres that could reach up to a few voxels of distance. The calibration step of diffusion described later in the manuscript (2.3.2) allowed us to adjust the maximum distance we need to take to properly simulate the diffusion (3.2). 
In Mosaic, diffusion takes place between two connected nodes i and $\mathrm{j}$ of the graph. The diffusive flux $J_{i j}$ is proportional to the diffusion coefficient $D_{i j}$ between the connected spheres $i$ and $j$, to the area of contact $S_{i j}$ and the difference in concentration $\Delta C_{i j}=C_{i}-C_{j}$ and is inversely proportional to the $d_{i j}$, Euclidean distance between the two centres of the spheres:

$$
J_{i j}=\frac{-D_{i j} S_{i j} \Delta C_{i j}}{d_{i j}}
$$

Since the spatial model embodied in Mosaic is discrete in both space and time, the assessment of the diffusion on each sphere i can be expressed as:

$$
\frac{d C_{i}}{d t}=\sum_{j}^{n} D_{i j} S_{i j} \frac{\Delta C_{i j}}{d_{i j}}
$$

where $d C_{i}$ is the concentration variation within sphere i during time $d t, n$ is the number of spheres connected to $\mathrm{i}$, and the sum is taken on all spheres $\mathrm{j}$ adjacent to $\mathrm{i}$.

If $\mathrm{i}$ and $\mathrm{j}$ have the initial connectivity (in blue Fig. 1a), the surface of the area $S_{i j}=\pi R_{i j}^{2}$. When i and j have additional connectivity (in black Fig. 1d), $S_{i j}$ can be equal to a few pixels that we estimated (subsection 3.2) by fitting the diffusion curves with that of the LBM.

\subsubsection{Biological component of Mosaic model}

In biological components (See figure in SI 1), dissolved organic matter (DOM) comes from the hydrolysis of SOM (soil organic matter) and POM (particulate organic matter). Bacteria grow by assimilating DOM and respire by producing carbon dioxide $\left(\mathrm{CO}_{2}\right)$. Bacterial cells are then transformed into SOM and DOM when they die. The parameters used to describe bacterial dynamics include the respiration rate, mortality rate, proportion of bacteria returning to DOM (the other fraction returning to SOM), decomposition rate of POM and SOM, maximum growth rate of bacteria, and constant of the half saturation of DOM (see Monga et al. 2014). The biological model does not consider the $\mathrm{O}_{2}$ limitation of respiration under anaerobic conditions.

\subsection{CT soil images}


Soil CT images, taken from Juyal et al. (2018), were obtained from the same soil brought at two different bulk densities. The resolution of the intermediate value (size of the pixel 24 $\mu \mathrm{m})$ is large enough to represent a set of pore classes related to microbiological activity and small enough to simulate diffusion on a millimetric image.

The soil used in this study is a sandy loam soil (sand, silt, clay: 71, 19 and 10\% soil mass, respectively) from the Bullion Field, which is an experimental site situated at the James Hutton Institute in Invergowrie (Scotland). A detailed description of the soil samples and methods used to produce CT images can be found in Juyal et al. (2018). Briefly, cylindrical containers $\left(3.4 \mathrm{~cm}^{3}\right.$; diam. $1.5 \mathrm{~cm}$, height $\left.1.7 \mathrm{~cm}\right)$ were packed with sieved soil to obtain bulk densities of 1.2 and $1.6 \mathrm{~g} \mathrm{~cm}^{-3}$. The soil samples were scanned with a high-resolution X-ray micro-Computed Tomography machine ( $\mu$ SIMCT Equipment: SIMBIOS Centre University of Abertay Dundee, Scotland) at $105 \mathrm{kV}, 96 \mu \mathrm{A}$, and 2,000 angular projections with 2 frames per second. Radiographs were reconstructed into 3D volumes at a resolution of $24 \mu \mathrm{m}$. Data were imported into VGStudiomax (Volumegraphics, Heidelberg, Germany) and converted into 24 $\mu m$ voxel-thick stacks and 8-bit greyscale bmp images. For the numerical simulations, an image consisting of $512 * 512 * 512$ voxels was extracted from the 3D stack (corresponding to a soil

sample of $1.8 \mathrm{~cm}^{3}$ ). Segmentation of the solid and pore phases was performed with an indicator kriging method (Houston et al., 2013). The segmented image had a total visible porosity of 17\% for the soil sample with a bulk density of $1.2 \mathrm{~g} \mathrm{~cm}^{-3}$ and $8 \%$ for the soil sample with a bulk density of $1.6 \mathrm{~g} \mathrm{~cm}^{-3}$.

\subsection{Modelling water distribution and diffusion with Mosaic}

\subsubsection{Modelling pore space and water distribution}

Water saturations of 20,50, 80 and $100 \%$ pore volume were selected. With Mosaic, the spheres were emptied of their water until the appropriate water saturation was reached. For this, we imposed different matric potentials, calculated the equivalent radius thresholds given by the 
Young-Laplace law, and then simulated the water saturation (Monga et al., 2008). From the 3D images, several indicators, such as primitive number, cluster number (cluster=set of connected pores), and connectivity, were calculated for each degree of water saturation and both bulk densities. The connectivity index was calculated as follow:

$\mathrm{CI}=$ (Number of Balls-Number of clusters)/(Number of balls-1)

For the subsequent simulations considering diffusion and mineralization, only water-filled pores were considered.

\subsubsection{Modelling and calibrating diffusion}

We simulated a DOM diffusion experiment (without microbial degradation) for the four water saturations and two soil bulk densities. We compared the Mosaic simulations with the simulated results obtained with the lattice Boltzmann model (LBM) of Genty and Pot (2013, 2014) because of its ability to simulate diffusion. For the LBM, the water distribution simulation was compared very favourably using synchrotron-based measurements of air-water interfaces at equilibrium for different water saturations (Pot et al., 2015), while the simulation of diffusion was compared favourably with the analytical solution of the diffusion equation in cubic sphere packing (Genty and Pot, 2014). The LBM was taken as the reference for testing the diffusion process in the Mosaic model.

We took a 512x512x300 area of the initial 512x512x512 CT image. As an initial condition, we imposed a DOM concentration of $426 \mu \mathrm{g} \mathrm{cm}{ }^{-3}$ for the different water saturations and bulk densities. DOM was located in pores on the upper edge of the image at a thickness of two voxels for the LBM and in the adjacent spheres for the Mosaic model (the average diameter of spheres was 2 voxels). We simulated diffusion for $14 \mathrm{~h}$. In both models, we used a molecular diffusion coefficient of DOM in water of $6.7310^{-6} \mathrm{~cm}^{2} \mathrm{~s}^{-1}$ (GRC, 1986). We compared the simulated diffusion profiles obtained with the LBM to those simulated with the two versions of 
Mosaic before and after the improvements described above (subsection 2.1.2). The only parameter fitted with Mosaic was the distance between non-adjacent spheres.

\subsection{Modelling organic matter mineralization with Mosaic}

\subsubsection{Organic matter distribution}

Different scenarios were carried out with dissolved organic matter or particulate organic matter (Table 1). For scenarios with DOM, $0.2895 \mathrm{mgC}$ of DOM was added to the water in the water-filled pores of the 3D images $\left(1.8 \mathrm{~cm}^{3}\right)$. This value corresponds to a concentration of $0.134 \mathrm{mgC} \mathrm{g}^{-1}$ soil for a soil density of $1.2 \mathrm{~g} \mathrm{~cm}^{-3}$, which is the same as the concentration used in the experiments described in Monga et al. (2014). We kept the mass of DOM the same regardless of the degree of water saturation and the soil density, which implies that the concentrations increased with decreasing water saturation degrees. DOM was distributed in all pore space homogeneously. The concentration of DOM was identical in all spheres. For scenarios with POM, POM was added in the same quantity as in the DOM scenarios, i.e., 0.2895 mgC for $1.8 \mathrm{~cm}^{3}$. POM was distributed in 1 , 10, or 100 patches or in all pore spaces ("homogeneous" treatment) of identical mass regardless of the scenario. For DOM, the amount of POM was the same regardless of the degree of water saturation or the soil density. Moreover, we ensured that POM was always placed in water-filled primitives, regardless of the degree of water saturation.

\subsubsection{Bacterial distribution}

We considered two scenarios of bacterial distribution into pore space: homogeneous and heterogeneous placement.

In the homogeneous distribution case, we assumed a random distribution of bacteria with a density of $10^{8}$ cells g $^{-1}$ soil, corresponding to the density of Juyal et al. (2019) for the soil used to obtain the CT images. This first scenario is called 'homogeneous placement" in which $10^{8}$ spots are occupied by bacteria. Each water-filled pore voxel contains a few bacterium. In 
the heterogeneous distribution case, we chose the model of bacterial distribution described in Raynaud \& Nunan (2014) because it was built on real observations of 2D soil thin sections. Briefly, their analysis indicated that bacterial distribution was aggregated in soils and could be modelled using the log Gaussian Cox process (LGCP), which is a point process with a random intensity measure. The approach used LGCP simulation for the initial distribution of bacteria, with parameters measured by Raynaud \& Nunan (2014). To start, the bacteria were put everywhere in the 3D space including in the solid phase. It was then necessary to remove those which were in the solid phase. Consequently, we had to change the initial bacteria density that we gave to the statistical model LGCP in order to obtain the same density as in the “homogeneous placement” case $\left(10^{8}\right.$ bacteria $\mathrm{g}^{-1}$ soil). Moreover, to produce more visually realistic distributions with dense cell aggregates and empty spaces, cells were kept only if they belonged to the first 1000 voxels with the highest biomass. This second scenario is called "heterogeneous placement."

In the homogeneous scenario, there were bacteria in each Mosaic sphere (around 300000 balls for saturation scenarios, see Table 2). In the heterogeneous scenario, bacteria are aggregated and spread only in 1000 balls in saturation scenarios. We kept the same number of bacteria regardless of the degree of water saturation and the soil bulk density, which implies that the concentrations of bacteria increased when the water saturations decreased. To obtain the same number of bacteria by decreasing the saturation, we had to reposition the bacteria in the water-filled pore. The bacteria were repositioned in the water-filled sphere having the shortest distance from the empty water sphere containing the bacteria.

\subsubsection{Biological parameters}

We selected the biological parameters of the Mosaic model presented in Monga et al. (2014) because they were already used to simulate carbon mineralization by microbial degradation in real conditions successfully. Microbial parameters of the model (see 2.1.3) were 
taken from Arthrobacter sp. 9R (Monga et al., 2014). The respiration rate was set to $0.2 \mathrm{~d}^{-1}$, and the mortality rate was set to $0.5 \mathrm{~d}^{-1}$. The proportion of bacteria that was returned to DOM was set to 0.55 . The maximum growth rate of bacteria and half saturation were set to $9.6 \mathrm{~d}^{-1}$ and $0.001 \mathrm{gC} \mathrm{g}^{-1}$, respectively. The values of the decomposition parameters were taken from Iqbal et al. (2014) obtained by parameter calibration from carbon mineralisation during incubation of Maize residues mixed to a loamy soil. They found decomposition rates of POM and SOM set to $0.3 \mathrm{~d}^{-1}$ and $0.001 \mathrm{~d}^{-1}$, respectively. The decomposition of crop residues is not very sensitive to the soil texture but the decomposition of the soil organic matter (SOM) is sensitive to the clay content. Our soil is mostly sandy compare to the soil of Iqbal et al. (2014). As we studied the decomposition over a very short time (few days), the SOM has decomposed very little.

\subsubsection{Simulation of scenarios}

The scenarios were simulated with the Mosaic model because of its shorter computation time using the initial 512x512x512 CT image. The scenarios related to the placement of organic matter and microorganisms as described previously are presented in Table 1 for the two soil densities and the four water saturations (8 simulations for each placement scenario). We chose to simulate the cumulative $\mathrm{CO}_{2}$ value at 5 days to be able to carry out a large number of simulations.

\subsubsection{Proposal of a new indicator: the accessibility coefficient of POM for} bacteria

We proposed a new parameter called the accessibility coefficient (ACC) of organic matter for bacteria that we applied for the POM scenario with Mosaic. For its calculation, we considered the geodesic distance of POMs for the microorganisms. The shorter geodesic distance between bacteria and POM is the shorter water filled pore pathway that links bacteria and POM. In some cases, there is no such shortest pathway because there is a disconnection between the pores where POM is and the pores where bacteria are. Our results (3.3) showed the 
importance of the OM local concentration; therefore, we weighed the factor by the amount of POMs. We used the following equations:

For each $\mathrm{POM}_{\mathrm{j}}$ :

$$
A C C_{j}=M_{j} \sum_{i=1}^{N_{j}} \frac{1}{x_{i}^{j}}
$$

For all $\mathrm{POM}_{\mathrm{j}}$ :

$$
A C C=\frac{1}{\sum_{j=1}^{N} M_{j}} \sum_{j=1}^{N} A C C_{j}
$$

where $\mathrm{x}_{\mathrm{i}}^{\mathrm{j}}$ is the shortest geodesic distance between $\mathrm{POM}_{j}$ and bacteria $\mathrm{i}_{\mathrm{j}} \mathrm{N}_{\mathrm{j}}$ is the number of bacterial patches connected with $\mathrm{POM}_{\mathrm{j}}, \mathrm{M}_{\mathrm{j}}$ is the mass of $\mathrm{POM}_{\mathrm{j}}(\mathrm{mg} \mathrm{C})$ and $\mathrm{N}$ is the number of POM particles. All scenarios had the same POM mass of $0.2895 \mathrm{mgC}$ for $1.8 \mathrm{~cm}^{3}$ of soil. A programme based on Dijkstra's algorithm was used to calculate the shorter geodesic distance and the accessibility coefficient.

\section{Results}

\subsection{Modelling pore space and water distribution}

The Mosaic outputs showed distinct visual differences in porosity depending on the bulk densities and water saturations (Fig. 2). The low bulk density soil $\left(1.2 \mathrm{~g} \mathrm{~cm}^{-3}\right)$ had more connected pores, whereas the high bulk density soil $\left(1.6 \mathrm{~g} \mathrm{~cm}^{-3}\right)$ had a smaller and more fragmented porosity, with many small, isolated pores. The connectivity index increased with the degree of water saturation and with the bulk density (Table 2).

\subsection{Modelling and calibrating diffusion}

Pot et al. (2015) have already shown the ability of Mosaic and LBM to similarly simulate the location of water in pores (as shown in SI 2 and 3). Because the LBM was already tested for its ability to correctly model diffusion (Genty and Pot, 2014), its predictions have been taken 
as a reference to assess diffusion in the Mosaic model. By fitting the diffusion curves obtained with Mosaic on that of LBM, we optimized the distance between two adjacent balls for the Mosaic model. We found that this distance had to be equal to two voxels.

With the old version of Mosaic (Monga e al., 2014), the DOM mass profiles calculated with the LBM and Mosaic models were not close (SI 4). For example, diffusion in the LBM was faster than that in Mosaic for a soil bulk density of $1.6 \mathrm{~g} \mathrm{~cm}^{-3}$ and $100 \%$ water saturation. The summary of model efficiencies for all situations provided in Table 3 (2 soil bulk densities * 4 water saturations) also shows that model efficiencies were higher when Mosaic was run with the corrections described in paragraph 2.1 of this study. The correction of Mosaic, which consisted of increasing the connectivity between the spheres, made it possible to obtain a DOMmass profile curve very close to that of the LBM (Fig. 3) and increase the model efficiencies to 0.9 (Table 3). The results presented in Fig. 3 show that the diffusion of DOM was higher for high water saturations and low soil bulk densities in both models.

\subsection{OM decomposition: Scenario with Mosaic}

\subsubsection{DOM decomposition}

The simulation results suggest that more mineralization occurred when microorganisms were distributed everywhere in a homogeneous way (Fig. 4 A and B) than when they were distributed in a heterogeneous and patchy way (Fig. $4 \mathrm{C}$ and D). This is explained by the greater accessibility of the microorganisms to the substrate in the first case. Soil bulk density had little effect on mineralization rates for the homogeneous distribution of bacteria (comparison between Fig. 4A and B). However, when microorganisms were heterogeneously distributed, we found less mineralization in soil samples with a high bulk density than in soil with a low bulk density (Fig. $4 \mathrm{D}$ and C, respectively). This may be due to the lower diffusion rate of DOM under higher soil densities. We have shown previously that diffusion is indeed more limited when the bulk density of the soil is $1.6 \mathrm{~g} \mathrm{~cm}^{-3}$ compared to a bulk density of $1.2 \mathrm{~g} \mathrm{~cm}^{-3}$ (Fig. 3). 
The effect of water saturation on the mineralization curves changed according to the soil bulk density and microbial distribution. In Fig. 4A, the lower the degree of water saturation, the more mineralization increased. In this case, the concentration may play an important role because the decrease in the moisture content increased the local DOM concentration, as the total amount of DOM was the same in all simulations. The difference between the mineralization curves remained small in Fig. 4B, where the soil bulk density was higher, indicating that the influence of moisture content was lower in this situation. In Fig. 4C, mineralization curves are not ranked according to the degree of water saturation, which can be explained in this case by a combination of two effects: diffusion and concentration. The increase in moisture content increased diffusion but decreased the DOM concentration. The first factor has a positive effect on mineralization, whereas the second factor has a negative effect. The differences in mineralization rates between the different water saturations are larger for the heterogeneous microbial distribution (Fig. 4 C, D) than for the homogeneous distribution (Fig. 4A, B). This suggests that the impact of water saturation and soil bulk density on diffusion was higher in the case of heterogeneous bacterial distribution compared to a homogeneous distribution.

In summary, three factors were important in controlling the rate of mineralization in these scenarios. The ease of access of bacteria to the resource was influenced by their spatial distribution, diffusion and concentration of DOM, the last two influenced by the degree of water saturation.

\subsubsection{POM decomposition}

Similar to DOM, carbon mineralization was higher in the case of a homogeneous distribution of microorganisms than in the case of a heterogeneous distribution (Fig. 5A, B). In Fig. 5A, for the homogeneous distribution of microorganisms, the more concentrated the POM was, the greater the extent of $\mathrm{C}$ mineralization. As mentioned earlier, the fact that the 
concentration is high induces more mineralization, but the curves remain relatively close to each other. The red curve corresponding to the homogeneous distribution of the organic matter appeared to exhibit a slightly longer lag period at the onset of mineralization than in the other cases; however, over time, the curve tended asymptotically to the same mineralization rate.

In Fig. 5B, for the heterogeneous distribution of microorganisms, concentration alone could not explain the ranking of the mineralization curves. The scenario with a single POM spot had a higher $\mathrm{CO}_{2}$ mineralization rate because the organic matter concentration was very high, and we could check that a spot of bacteria was present in the same pore cluster as the organic matter spot. However, for the other cases, the order was reversed compared to the concentration. Mineralization rates were higher when the POM was dispersed because the probability that POM and bacteria occurred in the same pore cluster and were hence colocalized was higher for higher POM dispersion.

In summary, two factors were important in describing the extent of mineralization in these scenarios: the accessibility of microorganisms to the organic resource and the concentration of organic matter via its initial placement.

\subsection{Accessibility coefficients in POM placement scenarios}

In the scenarios of POM decomposition, we calculated the accessibility coefficient ACC presented in Eq. (6) (Fig. 6). We found that the greater the accessibility was, the greater the carbon mineralization was, with a linear correlation between the accessibility coefficient and the cumulative $\mathrm{CO}_{2}$ at 5 days. We found a correlation coefficient $\mathrm{r}^{2}$ of 0.6975 . In appendix 4, we can see that for a given bulk density and water content, the rankings of accessibility coefficients and cumulative $\mathrm{CO}_{2}$ were very similar. The choice of a cumulative $\mathrm{CO}_{2}$ value at 5 days is an arbitrary choice that we made at the beginning in order to carry out a large number of simulations. A longer period might have led to a correlation that is more accurate.

\section{Discussion}


Microbial degradation of organic matter in soil depends on the accessibility of the substrate to bacteria. More specifically, it depends on 1) their respective distance, 2) the diffusion of the substrate in the environment and 3) the amount of available substrate. The distance between bacteria and organic matter depends on their initial spatial distribution in soil. If this distance is high, then accessibility is limited by the diffusion process, which depends partly on the chemical species as well as on the local properties of the pore system, such as its connectivity, tortuosity and the degree of water saturation. The quantity of available resources depends on their local concentration.

\subsection{Factors impacting the accessibility}

\subsubsection{Impact of initial distance between bacteria and organic substrates:}

\section{Diffusion length}

The initial spatial distribution of bacteria in the soil had a large influence on the mineralization rate, as shown by the differences between curves Figs. 4A-4C, 4B-4D, and 5A5B. In the case where DOM and bacteria were uniformly located, decomposition was optimal. When bacteria were distributed heterogeneously, the spatial separation between them and OM led to longer diffusion lengths, and consequently, biodegradation was limited by diffusion. Indeed, diffusion curves (Fig. 3) showed that the diffusion of DOM after 14 hours could be limited to a 1-2 mm distance for a low degree of water saturation or a high soil bulk density.

Several studies in the literature have shown that maximizing the contact between degrading bacteria and substrates increases the mineralization degree. In contrast, when bacteria and substrate were heterogeneously distributed in a soil, the key factor controlling biodegradation was diffusion. Recous \& Angers (1997) and Iqbal et al. (2014) found that the smaller the particle sizes for the same overall amount of OM added were, the higher the mineralization rate was at the beginning. They attributed this to the closer contact of OM with the soil aggregates where bacteria are located. For a uniform distribution of SOM, Pagel et al. 
(2020) showed that a strong spatial clustering of microbial communities induced diffusionlimited C availability, which translated to lower decomposition degrees of $\mathrm{C}$ compounds. Pinheiro et al. (2015) found that bacteria could not degrade the solute after a few weeks when initially separated in soil by a distance of $1.7 \mathrm{~cm}$, although they could mineralize it when they were colocalized. A Euclidean distance of 4-5 mm separating bacteria and POM has been found to be beyond which the bacteria have difficulty accessing their resources (Gaillard et al., 1999; Portell et al., 2018).

In our scenarios, the water content did not change during simulations, and we always placed bacteria in the water-filled pores so that they were always active. In reality, the activity of bacteria can vary with the degree of water saturation because as the soil dries out, pores with larger diameters empty of water, thus rendering some of the bacteria inactive. Ruamps et al. (2011) showed that the degree of activity of bacteria varied according to the diameter of the pores in which they were located.

It should be noted that the behaviour predicted by these simulations applies strictly to bacteria for which biokinetics parameters were available and have been used as input in this modelling exercise. The situation may be different from other microorganisms. Modelling results obtained by Falconer et al. $(2012,2015)$ suggest that the behaviour of fungal hyphae is drastically different because hyphal growth can overcome high distances.

\subsubsection{Impact of diffusion in situations where degraders and substrate are not}

\section{initially colocalized}

Our simulation results show that the heterogeneous localization of bacteria in a pore space limits the degradation of the OM (Fig. 4C and 4D, Fig. 5B). On the one hand, the decrease in the degree of water saturation from 100 to $20 \%$ led to lower mineralization rates via decreased diffusion (Fig. 4C). On the other hand, the increase in soil bulk density led to a decrease in mineralization (difference between Fig. 4C and 4D) because the pore space was 
more disconnected, as shown in Table 2. As seen in the diffusion curves of Fig. 3, the diffusion of DOM after 14 hours was lower for low water saturations and for low soil densities and could be limited to a distance of only 1-2 mm.

For conditions where degraders and the substrate are not initially colocalized, Babey et al. (2017) showed that degradation is higher under wet conditions when higher diffusion delivers substrate towards bacterial hotspots. Vogel et al. (2015), in their simulations of dissolved organic carbon at the pore scale, also noted that an increased delay in DOM transport by diffusion, stemming from a lower degree of water saturation or a higher pore tortuosity, results in limited degrader activity when the initial distance between DOM and degraders is high.

Simulations of a DOM diffusion front initially distributed homogeneously on one face of the cube in the direction perpendicular to this face (Fig. 3) suggest that the diffusion front is virtually unidirectional, although the simulation was done in 3D space. Diffusion of the DOM in 3D space induces a greater limitation of DOM transfer because of its dilution, as already underlined by Babey et al. (2017). This is also the case in our scenario of heterogeneously distributed bacteria. If diffusion is limited to 1-2 $\mathrm{mm}$ in 1D space (as shown in Fig. 3), then in 3D space, an even greater limitation of diffusion may occur.

A notable limitation of our modelling approach comes from the CT image resolution, which is $24 \mu \mathrm{m}$; therefore, it does not allow the viewing of pores with diameters smaller than this resolution. These small pores can in principle participate in diffusion even if their diameter is very small. As all the scenarios have this resolution, we can assume that the comparison between the scenarios is not affected.

\subsubsection{Impact of local substrate concentration}

In our scenarios, the initial OM concentration was different between treatments due either to the increase in the degree of water saturation, which concentrated the DOM (in Fig. 
4A), or to the initial distribution of the POM in the pore space (Fig. 5A). Higher OM concentrations increased C mineralization (Fig. 4A and 5A). The Mosaic model uses Monod kinetics to simulate the growth rate of the microbial population as a function of organic matter concentration with an increasing logarithmic function.

In the DOM scenarios (Fig. 4A), the DOM concentration increased with decreasing degrees of water saturation and was multiplied by a factor of five when the water saturation decreased from 100 to $20 \%$. Regarding the bacterial growth curve relative to the DOM concentration of the Monod kinetic curve, these samples plot on the part of the curve where the bacterial growth rate increases proportionally to the DOM concentrations. This appears to explain why the mineralization curves of Fig. 4A decreased as the degree of saturation increased.

For the POM scenarios at a water saturation of 100\% (Fig. 5A), the homogeneous POM treatment distributed POM in 361874 patches (number of spheres at 100\% water saturation for a soil bulk density of $1.2 \mathrm{~g} \mathrm{~cm}^{-3}$ ), although the other scenarios distributed the same amount of POM in either 1, 10 or 1000 spheres. If we consider the microbial growth curve relative to the OM concentration using Monod kinetics, we obtain a very low microbial growth rate for the concentration calculated under the "homogeneous POM" distribution treatment and higher microbial growth rates close to the maximum for 100, 10 and 1 patch(s) treatments. This appears to explain why the mineralization curves of Fig. 5A decreased as the number of patches increased.

\subsubsection{Impact of all factors: distance between $\mathrm{OM}$ and bacteria, diffusion}

\section{coefficient and OM concentration}

In the context of the scenarios that have been carried out, we can classify the impact of the three factors in order of importance: the distribution of bacteria, the concentration of OM, and the diffusion rate. 
For most of our scenarios, the distribution of bacteria determined the magnitude of carbon mineralization. Babey et al. (2017) also showed that the initial separation distance between the substrate and degraders is the major control of degradation. In our results, the influence of water saturation on mineralization is comparatively smaller. The diffusion remains on the same order of magnitude even if we change the water saturation and soil density.

However, we obtained antagonistic effects between the different factors. For example, the negative effect of the larger transit time of the substrate to the hotspot may be compensated by the positive effect of a higher concentration, as shown in Fig. 5B, where the mineralization of a single POM spot was higher than the mineralization in the homogeneous POM distribution. Portell et al. (2018) also found, in some scenarios, that bacterial growth was higher when bacteria were placed far from the POM compared to other scenarios where the bacterial spot was placed near the POM because the concentration of POM was greater in the first scenarios.

\subsubsection{Limitation of our approach}

The identification of accessibility parameters through scenario modelling, which we have described above, is admittedly limited in scope at this stage by the fact that the model, in its current version, does not encompass a number of microbial processes that we know, or at least strongly suspect, to be of significance. To a large extent, we did not want to make the model excessively complex in order to be able to analyse clearly the steps involved in the scenario modelling and the subsequent identification of accessibility parameters. To that end, we opted to focus our attention to a limited number of factors such as water content, soil structure, and the initial location of microorganisms. The model does not take into account bacterial motility, because we do not have enough information on this process at this stage to parameterize it in the model. Clearly, this process could change accessibility on a very fine scale (Valdes Parada et al., 2009). In addition, the model does not simulate the production of extracellular enzymes by microorganisms. They can diffuse to the organic matter, be degraded, 
and be adsorbed on the soil minerals, rendering them inactive. To explicitly simulate the action of enzymes would require that a number of parameters be added to the model, which we do not know very well. We have chosen instead to consider a decomposition rate of POMs, which implicitly simulates the solubilization of POMs by enzymes. A further limitation of the model is that it takes only one microbial species into account. Using the same model, we have already tested several species of bacteria (with different mineralisation and growth rates) but separately from each other (Monga et al., 2014). The presence of several species of microorganisms would indeed have led to interactions such as competition and mutualism. Portell et al. (2018) carried out modeling scenarios also in a 3D space to look at the influence of the spatial distribution of organic matter and bacterial diversity on the carbon mineralization activity. Their simulations evinced little influence of bacterial competition on the global simulated carbon mineralisation of organic matter. The experiments carried out by Banerjee et al. (2016) showed that the rate of organic matter decomposition remained similar while the abundance of different bacterial and fungal groups changed up to 300 -folds under different soil treatments, indicating high functional redundancy in soils. In our model, we can only simulate the action of bacteria. Indeed, to simulate the mineralization activity of fungi, we should place the fungi in several spheres each, while each sphere of Mosaic represents a biological entity containing bacteria. Fungal propagation in soil porosity and the effect of water on their behaviour is very complex. Falconer et al. (2012) simulated in 3D the effect of soil architecture and water distribution on fungal propagation in the soil. They showed that the increase of water content decreased fungal colonization, because of the decrease of connected air-filled pores in which fungi spread preferentially. These processes linked to fungal properties would require significant changes in the structure of the model. In future studies, we will improve the representation of microorganisms in order to look at the assumptions that it is reasonable to make for more accurate carbon mineralization simulations. 


\subsection{Accessibility coefficient}

In this study, we have shown that i) our Mosaic mineralization model is very sensitive to the localization of bacteria and, consequently, 2) there is a relationship between mineralization and the distance between $\mathrm{OM}$ and bacteria. We found a linear relationship between the accessibility coefficient and the cumulative mineralized $\mathrm{CO}_{2}$ (Fig. 6). This accessibility coefficient represents an average geodesic distance between the $\mathrm{OM}$ and the bacteria, weighted by the OM concentration (Eq. 4 and 5). Pinheiro et al. (2015) also showed, through an experimental approach, that the greater the distance between organic compounds and decomposers was, the less intense the mineralization.

In our modelling approach, OM is arbitrarily placed, and bacteria are placed using the model of Raynaud \& Nunan (2014). In the future, we could validate our approach by measuring the accessibility coefficient with 3D images of stained OM, on which we could also locate the presence of microorganisms around the OM. For OM, it is possible, through staining methods (as developed by Peth et al., 2014), to look at their location in 3D pore space. However, it is more complicated to visualize microorganisms in 3D pore space. The approach developed by Raynaud \& Nunan (2014), for example, is quite difficult to implement.

Rawlins et al. (2016) attempted to calculate OM accessibility using 3D CT images (6.6 $\mu \mathrm{m}$ resolution) with stained OM. Accessibility to OM was calculated from the distances to the pores that surrounded OM. They implicitly assumed that the microorganisms were in these pores. They could not find a relationship between $\mathrm{OM}$ accessibility and the microbial respiration measured in these same samples. The accessibility calculated as the distance of OM to the nearest pores is not equivalent to the distance between $\mathrm{OM}$ and microorganisms because the latter may not be everywhere or are not active everywhere.

Iqbal et al. (2014) calculated a contact coefficient between soil and OM for a model using first-order kinetics to describe mineralization. They found a relationship between the intensity 
of mineralization and the specific surface area of added fresh organic matter (FOM). This relationship shows that the larger the specific surfaces, the more $\mathrm{CO}_{2}$ emissions there are. They successfully simulated the measured $\mathrm{CO}_{2}$. Their approach makes the implicit assumption that microorganisms are everywhere around $\mathrm{OM}$ and therefore that the larger the specific surface area is, the better the contact between the FOM and the microorganisms. Indeed, in their case, we can assume that the microorganisms quickly colonize the FOM, coming from crop residues, which had recently been added to the soil. In the case of OM already present and that partly decomposed, it is possible that the microorganisms are no longer necessarily in the surrounding pores, which explains the conclusions of Rawlins et al. (2016).

\section{Conclusion}

In this work, we carried out simulations of carbon mineralization at the $\mu \mathrm{m}$ scale in soil with the 3D Mosaic model. The model was improved to better simulate the diffusion process. Among the input factors that we considered were the placement of bacteria and organic matter, the degree of water saturation, and the soil architecture via the soil bulk density. We proposed an accessibility coefficient that encapsulates the microscale distribution. This accessibility coefficient was correlated with mineralized carbon flux for different scenarios of particulate organic matter placement. In the future, it would be interesting to develop an automatic procedure to calculate this accessibility parameter for a large number of scenarios, for example, for other soil structures, to verify to what extent it is correlated with carbon mineralization in all situations. We should also validate our approach using real 3D images of soil on which we could locate the presence of microorganisms around the OM.

\section{Acknowledgements}

The research described in this article was made possible by the financial support of the ANR Project Soil- $\mu 3 D$ (Number ANR-15-CE01-0006-01) 


\section{References}

Babey, T., Vieublé-Gonod, L., Rapaport, A., Pinheiro, M., Garnier, P., \& de Dreuzy, J-R. (2017). Spatiotemporal simulations of 2,4-D pesticide degradation by microorganisms in 3D soil-core experiments. Ecological modelling, 344, 48-61.

Banerjee, S; Kirkby, CA; Schmutter, D; Bissett, A; Kirkegaard, JA; Richardson, AE (2016). Network analysis reveals functional redundancy and keystone taxa amongst bacterial and fungal communities during organic matter decomposition in an arable soil. Soil Biology \& Biochemistry, 97, 188-198, DOI: 10.1016/j.soilbio.2016.03.017

Baveye, P. C., Otten, W., Kravchenko A., Balseiro Romero, M., Beckers, E., Chalhoub, M., Darnault, C., Eickhorst, T., Garnier, P., Hapca S., Monga O., Mueller, C. W., Nunan, N., Pot, V., Schlüter, S., Schmidt, H., \& Vogel, H.-J. (2018). Emergent properties of microbial activity in heterogeneous soil microenvironments: Different research approaches are slowly converging, yet major challenges remain. Frontiers in Microbiology, 9, article 1929

Chakrawal, A., Herrmann, A.M., Koestel, J., Jarsjo, J., Nunan, N., Katterer, T., \& Manzoni, S. (2020). Dynamic upscaling of decomposition kinetics for carbon cycling models. Geoscientific Model Development, 13, 1399-1429, Doi: 10.5194/gmd-13-1399-2020

Dungait, J.A.J., Hopkins, D.W., Gregory, A.S., \& Whitmore, A.P. (2012). Soil organic matter turnover is governed by accessibility not recalcitrance. Global Change Biology, 18, 17811796, Doi: 10.1111/j.1365-2486.2012.02665.x

Gaillard, V., Chenu, C., Recous, S., \& Richard, G. (1999). Carbon, nitrogen and microbial gradients induced by plant residues decomposing in soil. European Journal of Soil Science, 50(4), 567-578, Doi: 10.1046/j.1365-2389.1999.00266.x

Garnier, P., Cambier, C., Bousso, M., Masse, D., Chenu, C., \& Recous S. (2008). Modelling the influence of soil-plant residue contact on carbon mineralization: Comparison of a compartmental approach and a 3D spatial approach. Soil Biology and Biochemistry, 40, 2754-2761. 
Falconer, R.E., Houston, A.N., Otten, W., \& Baveye, P.C. (2012). Emergent behavior of soil fungal dynamics: Influence of soil architecture and water distribution. Soil Science, 177, 111-119, Doi: 10.1097/SS.0b013e318241133a

Falconer, R. E., Battaia, G., Schmidt, S., Baveye, P., Chenu, C., \& Otten, W. (2015). Microscale heterogeneity explains experimental variability and non-linearity in soil organic matter mineralisation. PLoS One 10:e0123774. doi: 10.1371/journal.pone.0123774

Genty, A., \& Pot, V. (2013). Numerical simulation of 3D liquid-gas distribution in porous media by a two-phase TRT Lattice Boltzmann method. Transport in Porous Media, 96, 271294, Doi: 10.1007/s11242-012-0087-9

Genty, A., \& Pot, V. (2014). Numerical calculation of effective diffusion in unsaturated porous media by the TRT Lattice Boltzmann method. Transport in Porous Media, 105, 391-410, Doi: 10.1007/s11242-014-0374-8

Houston, A. N., Otten, W., Baveye, P. C., \& Hapca, S. (2013a). Adaptive-window indicator kriging: a thresholding method for computed tomography images of porous media. Computer \& Geosciences. 54, 239-248. doi: 10.1016/j.cageo.2012.11.016

Iqbal A., Garnier, P., Lashermes, G., \& Recous, S. (2014). A new equation to simulate the contact between soil and maize residues of different sizes during their decomposition. Biology and Fertility of Soils, 50, 645-655.

Juarez, S., Nunan, N., Duday, A.C., Pouteau, V., Schmidt, S., Hapca, S., Falconer, R., Otten, W., \& Chenu, C. (2013). Effects of different soil structures on the decomposition of native and added organic carbon. European Journal of Soil Biology, 58, 81-90, Doi: 10.1016/j.ejsobi.2013.06.005

Juyal, A., Eickhorst, T., Falconer, R., Baveye, P.C., Spiers, A., \& Otten, W. (2018). Control of pore geometry in soil microcosms and its effect on the growth and spread of Pseudomonas and Bacillus sp. Frontiers in Environmental Science, 6, 73, Doi: 10.3389/fenvs.2018.00073 
Juyal, A., Otten, W., Falconer, R., Hapca, S., Schmidt, H., Baveye, P.C., \& Eickhorst, T. (2019). Combination of techniques to quantify the distribution of bacteria in their soil microhabitats at different spatial scales. Geoderma, 334, 165-174, Doi: 10.1016/j.geoderma.2018.07.031

Kravchenko, A.N., \& Guber, A.K. (2017). Soil pores and their contributions to soil carbon processes. Geoderma, 287, 31-39, Doi: 10.1016/j.geoderma.2016.06.027

Manzoni, S., \& Porporato, A. (2009). Soil carbon and nitrogen mineralization: Theory and models across scales. Soil Biology and Biochemistry, 41, 1355-1379, Doi: 10.1016/j.soilbio.2009.02.031

Monga, O., Bousso, M., Garnier, P., \& Pot, V. (2008). 3D geometrical structures and biological activity: application to soil organic matter microbial decomposition in pore space. Ecological Modelling 216 : 291-302.

Monga O., P. Garnier, V. Pot, E. Coucheney, N. Nunan, W. Otten, C. Chenu. 2014. Simulating microbial degradation of organic matter in a simple porous system using the 3D diffusion based model MOSAIC. Biogeosciences 11, 2201-2209.

Ngom FN., Garnier P., Monga O., Peth S. 2011. Extraction of 3-D soil pore space from microtomography images using a geometrical approach. Geoderma 163, 127-134.

Pagel, H., Kriesche, B., Uksa, M., Poll, C., Kandeler, E., Schmidt, V., \& Streck, T. (2020). Spatial control of carbon dynamics in soil by microbial decomposer communities. Frontiers in environmental Science, 8, Article 2. Doi: 10.3389/fenvs.2020.00002

Peth, S., Chenu, C., Leblond, N., Garnier, P., Nunan, N., Pot, V., Ogurreck, M., \& Beckmann, F. (2014). Localization of soil organic matter in soil aggregates using synchrotron-based Xray microtomography. Soil Biology \& Biochemistry, 78, 189-194.

Pinheiro, M., Garnier, P., Béguet, J., Martin Laurent, F., \& Vieublé Gonod, L. (2015). The millimeter-scale distribution of 2,4-D and its degraders drive the degradation of 2,4-D at the soil core scale. Soil Biology and Biochemistry, 88: 90-100. 
Portell, X., Pot, V., Garnier, P., Otten, W., \& Baveye, P. (2018). Microscale heterogeneity of the spatial distribution of organic matter can promote bacterial biodiversity in soils: Insights from computer simulations. Frontiers in Microbiology, 9, Article 1583.

Pot, V., Peth, S., Monga, O., Vogel, L. E., Genty, A., Garnier, P., Vieuble-Gonod, L., Ogurreck, M., Beckmann, F., \& Baveye, P C. (2015). Three-dimensional distribution of water and air in soil pores: Comparison of two-phase TRT lattice-Boltzmann and morphological model outputs with synchrotron X-ray computed tomography data. Advances in Water Resources, 84, 87-102.

Raynaud, X., \& Nunan, N. (2014). Spatial ecology of bacteria at the microscale in soil. Plos One, 9, Article Number: e87217, Doi: 10.1371/journal.pone.0087217

Rawlins, B.G., Wragg, J., Reinhard, C., Atwood, R.C., Houston, A., Lark, R.M., \& Rudolph, S. (2016). Three-dimensional soil organic matter distribution, accessibility and microbial respiration in macroaggregates using osmium staining and synchrotron X-ray computed tomography. Soil, 2, 659-671, Doi: 10.5194/soil-2-659-2016

Recous, S., \& Angers, D.A. (1997). Decomposition of wheat straw and rye residues as affected by particle size. Plant and Soil, 189(2), 197-203, Doi: 10.1023/A:1004207219678

Ruamps, LS; Nunan, N; Chenu, C. (2011). Microbial biogeography at the soil pore scale. Soil Biology \& Biochemistry, 43(2), 280-286, Doi: 10.1016/j.soilbio.2010.10.010

Valdes-Parada, F. J.; Porter, M. L.; Narayanaswamy, K.; Ford, R. M.; Wood, B. D. (2009). Upscaling microbial chemotaxis in porous media. Advances in Water Resource, 32, 14131428. doi: 10.1016/j.advwatres.2009.06.010

Vogel, L., Makowski, D., Garnier, P., Vieublé-Gonod, L., Raynaud, X., Nunan, N., Coquet, Y., Chenu, C., Falconer, R., \& Pot V. (2015). Modeling the effect of soil meso- and macropores topology on the biodegradation of a soluble carbon substrate. Advances in Water Resources, 83, 123-136. 
Figures

Fig. 1: graph with initial connectivity (in blue, a), creation of connectivity with Delaunay triangulation (in black, b), graph with initial and additional connectivity (in blue and black, c): correction in order to remove the unnecessary arcs (in red, d).

Fig. 2: 2D soil Images of 1.2 and $1.6 \mathrm{~g} / \mathrm{cm}^{3}$ densities with water saturations of 0 , $20,50,80 \%$ simulated with Mosaic model (grey is the water filled porosity and black is the air filled porosity, white is the soil matrix)

Fig. 3: Profiles of DOM mass over the length of the sample after $14 \mathrm{~h} 30$ of simulation (for the two soil densities and for two water saturations): comparison between LBM and Mosaic model (after the corrections of the MOSAIC model). In the case of the Mosaic model, the quantity of DOM of each soil layer is obtained by summing up the DOM contained in all the spheres whose centres belong to the layer.

Fig. 4: Modelling scenarios with Mosaic of $\mathrm{CO}_{2}$ mineralisation for homogeneous distribution of dissolved organic carbon for homogeneous distribution of bacteria (Fig. A and B) or heterogeneous distribution of bacteria (Fig. C and D), for a soil density of 1.2 g.cm3 (Fig. A and C) and 1.6 g.cm3 (Fig. B and D) and at water saturations from $20 \%$ to $100 \%$ 
Fig. 5: Modelling scenarios with Mosaic of $\mathrm{CO}_{2}$ mineralisation of particulate organic matter distributed in 1, 10, 100 spots or homogeneously with homogeneous distribution of bacteria (Fig. A) or heterogeneous distribution of bacteria (Fig. B) for a soil density of $1.2 \mathrm{~g} \cdot \mathrm{cm}^{3}$ at $100 \%$ of water saturation.

Fig. 6: Relationship between accessibility coefficients of organic matter for microorganisms calculated with Mosaic and cumulative $\mathrm{CO}_{2}$ emissions simulated at 5 days for the different scenarios of POM distribution for the soil density of $1.2 \mathrm{~g} / \mathrm{cm}^{3}$ and $1.6 \mathrm{~g} / \mathrm{cm}^{3}$ at the degree of water saturation of $100 \%$ and $50 \%$ and for heterogeneous distribution of microorganisms (see SI 5). 
Tables

Table 1: Scenarios for the simulation of organic matter decomposition with Mosaic model

Table 2: Quantitative description of the water filled pore space from Mosaic model based on a geometrical approach using the direct segmented images (numbers are given from $512^{3}$ voxels images with a resolution of $24 \mu \mathrm{m}$ and a total volume of $1.8 \mathrm{~cm}^{3}$ ).

Table 3: Model Efficiency $(E F)^{*}$ is calculated for simulations of DOM concentrations at $14 \mathrm{H} 30$ without and with diffusion correction of MOSAIC, for all situations : 2 soil densities $\times 4$ water saturations. LBM results are considered as reference to fine-tune Mosaic simulations. 
Fig. 3
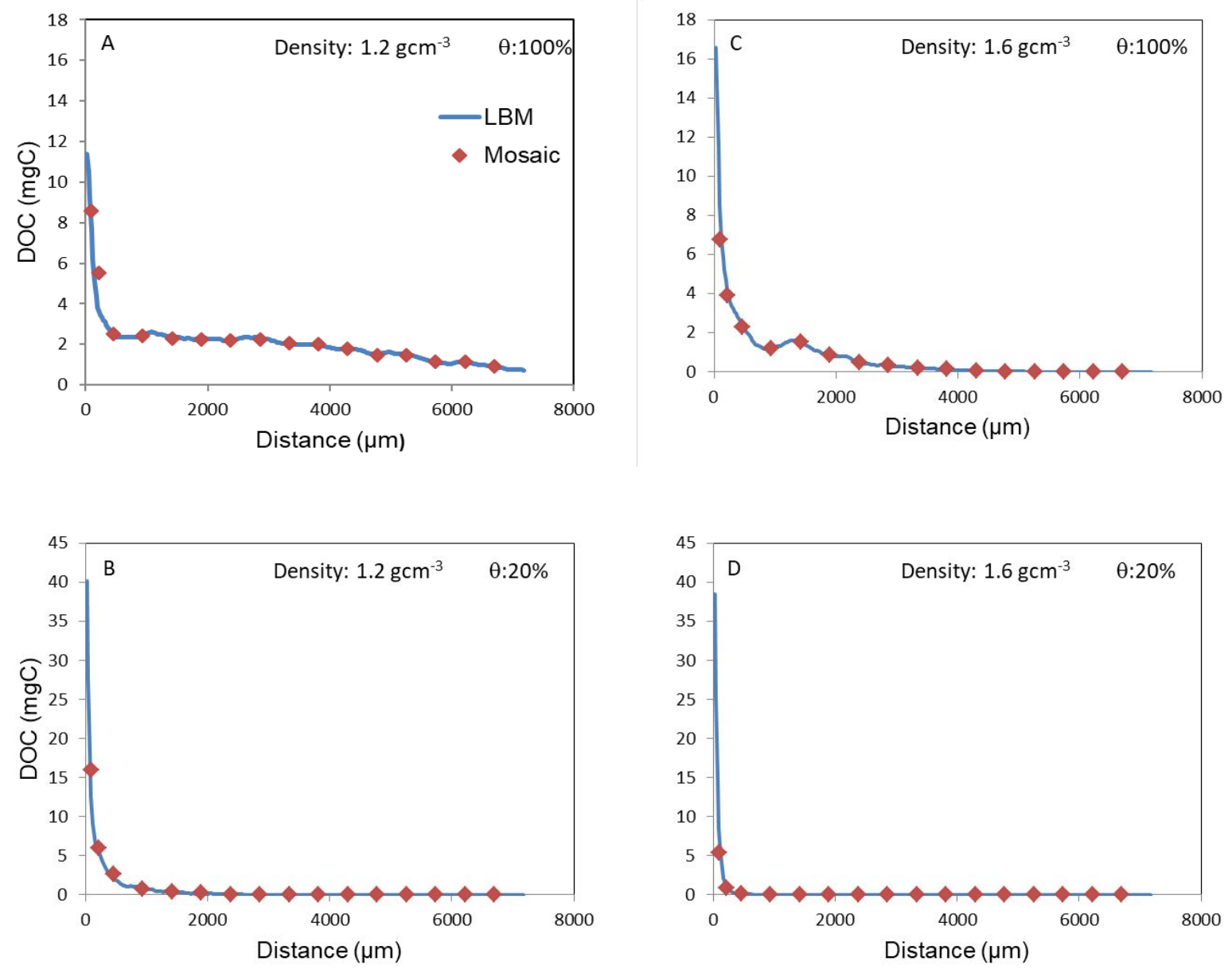

This article is protected by copyright. All rights reserved. 
Fig. 4

Soil density : $1.2 \mathrm{~g} \mathrm{~cm}^{-3}$

Soil density : $1.6 \mathrm{~g} \mathrm{~cm}-3$
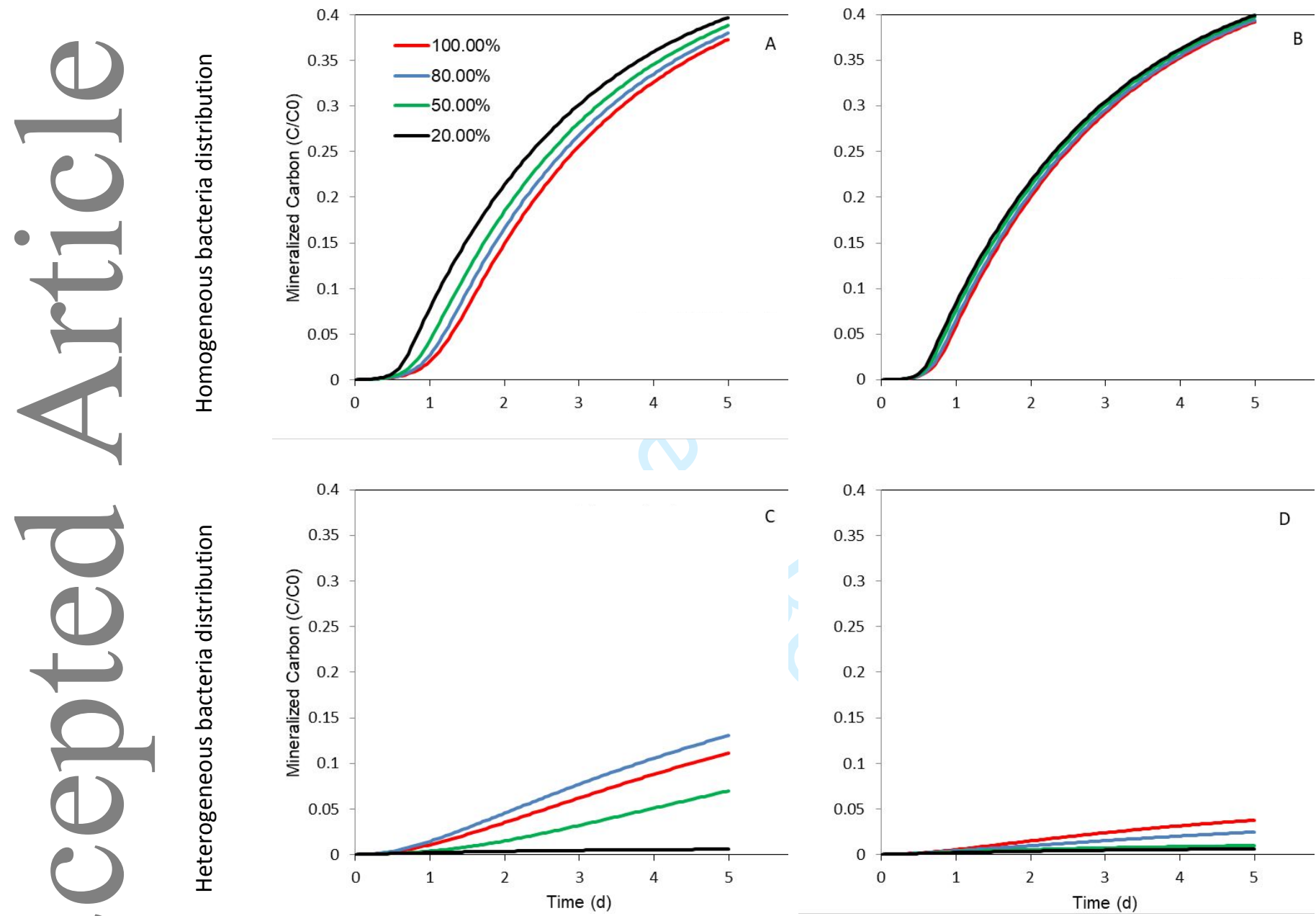

This article is protected by copyright. All rights reserved. 
Fig. 6

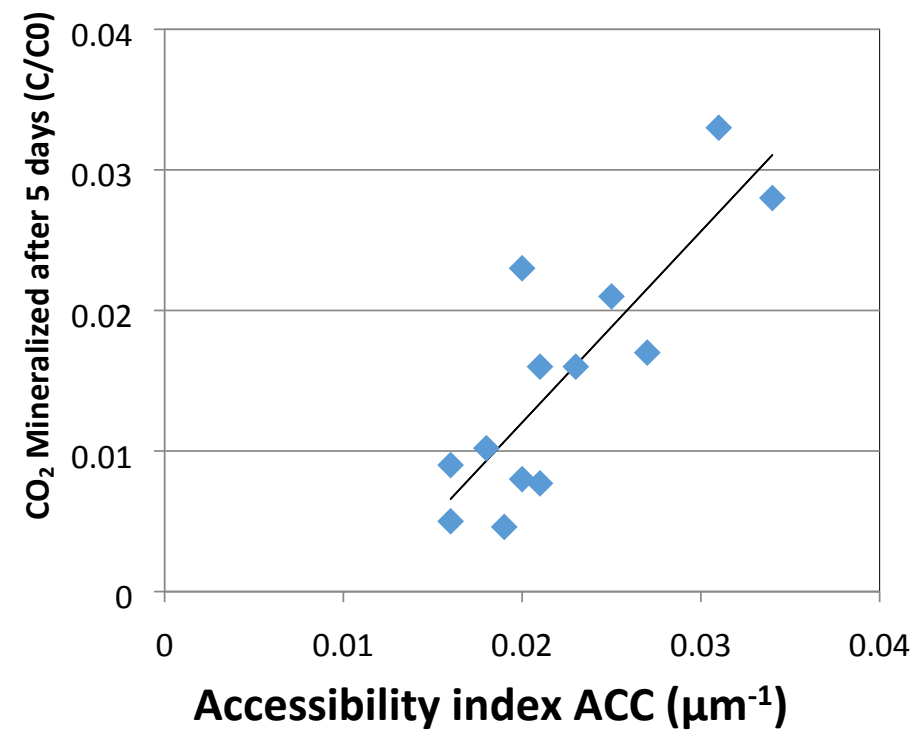

This article is protected by copyright. All rights reserved. 
Table 1: Scenarios for the simulation of organic matter decomposition with Mosaic model

Microorganism distribution

Homogeneous Heterogeneous*

1000 spots

\begin{tabular}{|c|c|c|c|}
\hline \multirow[b]{2}{*}{ DOC } & \multirow{3}{*}{ Homogeneous } & Scenario 1 & Scenario 2 \\
\hline & & 2 densities $x$ & 2 densities $x$ \\
\hline \multirow{4}{*}{ Distribution } & & 4 water saturations & 4 water saturations \\
\hline & & Scenario 3 & Scenario 4 \\
\hline & Homogeneous & 2 densities $x$ & 2 densities $x$ \\
\hline & & 4 water saturations & 4 water saturations \\
\hline \multicolumn{4}{|l|}{ POM } \\
\hline \multirow[t]{4}{*}{ Distribution } & Heterogeneous & Scenario 5 & Scenario 6 \\
\hline & 100 spots & 2 densities $x$ & 2 densities $x$ \\
\hline & 10 spots & 4 water saturations & 4 water saturations \\
\hline & 1 spots & & \\
\hline
\end{tabular}

*(simulated with the model of Raynaud and Nunan, 2014) 
Table 2: Quantitative description of the water filled pore space from Mosaic model based on a geometrical approach using the direct segmented images (numbers are given from $512^{3}$ voxels images with a resolution of $24 \mu \mathrm{m}$ and a total volume of $\left.1.8 \mathrm{~cm}^{3}\right)$.

\begin{tabular}{|c|c|c|c|c|c|c|}
\hline densité & $\theta(\%)^{*}$ & $\begin{array}{l}\text { Primitive } \\
\text { Number }\end{array}$ & $\begin{array}{l}\text { Water } \\
\text { filled } \\
\text { Porosity } \\
\%\end{array}$ & $\begin{array}{l}\text { Water } \\
\text { filled } \\
\text { Cluster } \\
\text { Number }\end{array}$ & $\begin{array}{l}\text { Porosity of } \\
\text { bigger cluster } \\
\text { (filled of water) }\end{array}$ & $\begin{array}{l}\text { Connectivity } \\
\text { Index } \mathrm{Cl}\end{array}$ \\
\hline \multirow{4}{*}{$\begin{array}{c}1.2 \\
\mathrm{~g} / \mathrm{cm} 3\end{array}$} & 100 & 361874 & 11.92 & 1616 & 11.51 & 0.9956 \\
\hline & 80 & 360535 & 9.97 & 1645 & 9.55 & 0.9954 \\
\hline & 50 & 350490 & 6.3 & 2035 & 5.57 & 0.9942 \\
\hline & 20 & 295511 & 2.39 & 12558 & 0.0017 & 0.9575 \\
\hline \multirow{4}{*}{$\begin{array}{c}1.6 \\
\mathrm{~g} / \mathrm{cm} 3\end{array}$} & 100 & 282307 & 5.44 & 5998 & 1.47 & 0.9788 \\
\hline & 80 & 280936 & 4.55 & 6028 & 1.01 & 0.9785 \\
\hline & 50 & 267029 & 2.87 & 7061 & 0.02 & 0.9736 \\
\hline & 20 & 220494 & 1.35 & 18534 & 0.0006 & 0.9159 \\
\hline
\end{tabular}

* expressed the percentage of the water filled porosity 
Table 3: Model Efficiency (EF)* is calculated for simulations of DOM concentrations at $14 \mathrm{H} 30$ without and with diffusion correction of MOSAIC, for all situations : 2 soil densities $\times 4$ water saturations. LBM results are considered as reference to fine-tune Mosaic simulations.

Density $1.2 \mathrm{~g} / \mathrm{cm} 3$

$\theta: 100 \%$

$\theta: 80 \%$

$\theta: 50 \%$

$\theta: 20 \%$

$\theta: 100 \%$

$\theta: 80 \%$

$\theta: 50 \%$

$\theta: 20 \%$
EF without

- Mosaic

correction

(1)

0.45

0.45

0.93

0.58

0.61

0.74

0.79

EF with

Mosaic

0.90

0.93

0.91

0.95

0.91

0.90

0.87

0.61

correction

$* \quad E F=1-\frac{\sum_{i=1}^{n}\left(S_{i}-m_{i}\right)^{2}}{\sum_{i=1}^{n}\left(m_{i}-\bar{m}\right)^{2}}$

where $S_{i}, m_{i}$ and $\bar{m}$ are the DOM concentration calculated from MOSAIC in layer $i$, the DOM concentration calculated from LBM in layer $i$ and the mean value calculated from LBM over the $n$ all layers of the sample, respectively. 